\title{
Panniculectomy Outcomes by Body Mass Index: an Analysis of 12,732 Cases
}

\author{
Joshua B. Cadwell $^{1} \cdot$ Salma Ahsanuddin $^{1} \cdot$ Haripriya S. Ayyala ${ }^{1} \cdot$ Ashley Ignatiuk $^{1}$ (i) \\ Received: 26 March 2021 / Revised: 27 April 2021 / Accepted: 5 May 2021 / Published online: 9 June 2021 \\ (C) This is a U.S. government work and not under copyright protection in the U.S.; foreign copyright protection may apply 2021
}

\begin{abstract}
Purpose With an increasing rate of obesity in the USA, bariatric surgery has become widespread, resulting in a greater number of patients seeking panniculectomy. The authors aim to determine the complication profile of panniculectomies by body mass index (BMI).

Methods The 2012-2018 National Surgical Quality Improvement Program database was queried for all panniculectomy cases. Patients were assigned to a category by their calculated BMI. Rates of complications were compared across BMI ranges. Demographics, comorbidities, and perioperative factors were compared between those with and without complications. Multivariable analyses were performed to analyze the associations between BMI ranges and post-surgical complications.

Results Twelve thousand seven hundred thirty-two cases were analyzed, of which 1759 (13.8\%) had at least one postoperative complication. As BMI increased, patients were more likely to experience postoperative complications $(p<0.001)$. Patients experiencing complications were more likely to be male, older, of a higher BMI group, have a higher American Society of Anesthesiologists Personal Status classification, be an inpatient, have various comorbidities, or be undergoing a concurrent procedure. On multivariable analysis, patients who were overweight $(\mathrm{OR}=1.24, p=0.039)$, with class $1(\mathrm{OR}=1.72, p<0.001)$, class $2(\mathrm{OR}=2.10, p<0.001)$, or class $3(\mathrm{OR}=3.01, p<0.001)$ obesity were more likely to have a postoperative complication. Wound complications were particularly prevalent in patients who were overweight ( $\mathrm{OR}=1.77, p=0.001$ ) or with class 1 $(\mathrm{OR}=2.59, p<0.001)$, class $2(\mathrm{OR}=4.05, p<0.001)$, or class $3(p=5.84, p<0.001)$ obesity compared to non-overweight patients. Conclusion A higher BMI is associated with more postoperative complications, particularly wound healing complications, following panniculectomy in a dose-dependent manner.
\end{abstract}

Keywords Body mass index $\cdot$ Panniculectomy $\cdot$ Complications $\cdot$ NSQIP $\cdot$ Plastic surgery $\cdot$ Surgery

\section{Introduction}

The obesity pandemic continues to be a large-scale problem in national healthcare, serving as one of the leading causes of

\footnotetext{
Key Points

- This study analyzes the effect of BMI on complications following panniculectomy.

- Patients with higher body mass indices experienced more postoperative complications.

- Wound healing complications were particularly more likely with increasing BMI.
}

\section{Ashley Ignatiuk} ai253@njms.rutgers.edu

1 Division of Plastic and Reconstructive Surgery, Department of Surgery, Rutgers New Jersey Medical School, 140 Bergen Street, Suite E1620, Newark, NJ 07103, USA preventable deaths in the USA [1]. While several public health prevention policies have been implemented, the prevalence of obesity has consistently increased since 1999 , rising to $42.4 \%$ in 2017-2018. This problem is hypothesized to continue to worsen due to the stresses of the COVID-19 pandemic [2-5]. By 2030, obesity prevalence in the USA is estimated to reach a staggering $50 \%$ [6]. To address the rising obesity rates, the number of bariatric surgeries has similarly increased, with an approximately $10 \%$ rise in procedures from just 2015 to 2016 $[7,8]$.

Following rapid weight loss, bariatric patients may continue to have a hanging abdominal panniculus. Described by Petty et al., the "panniculus morbidus" often results in poor ambulation, intertriginous yeast infections, cellulitis, abscesses, and inadequate psychosocial health, supporting the need for surgical intervention [9]. Thus, panniculectomy has served as the mainstay treatment for such patients and can be 
performed both at the time of gynecologic, hernia, or bariatric surgery or following surgery [10-12]. The number of panniculectomies performed in the USA has been reported to increase steadily over the past decade, likely at least partly due to the concomitant increase in the number of bariatric procedures being performed [13]. Thus, with the continued rise in obesity prevalence in the USA, the number of patients seeking bariatric surgery and subsequent panniculectomy is also likely to increase.

While patient satisfaction after panniculectomy has been reported to be high, such surgeries are not without complications, with rates as high as 56\% [14-16]. Minor complications reported in the literature include cellulitis, small abscesses, seromas, delayed wound healing, and epidermolysis, while major complications included hematomas, skin necrosis, and wound dehiscence, among others [17-19]. Complication rates have been directly related to increased BMI, larger panniculus sizes, hypertension, and diabetes [17, 20]. However, research is lacking on whether or not patients with higher weight, particularly at different categories of increased BMI, are predisposed to some complications over others. In this study, we aim to assess the impact of increasing body mass indices on the complication profile of panniculectomy.

\section{Methods}

\section{Database}

The National Surgical Quality Improvement Program (NSQIP) is a de-identified national database established to study postsurgical outcomes with the goal of improving patient care [21]. Each year, data on millions of surgeries are collected from hospitals across the USA and compiled into the database. The Institutional Review Board (IRB) of Rutgers New Jersey Medical School does not consider work done with publicly available de-identified databases to be human subject research. Therefore, IRB approval for this study was not required.

\section{Patient Sample and Extracted Variables}

A retrospective analysis using the 2012-2018 NSQIP database was performed. Panniculectomy cases were identified using the CPT code of 15830 , in a manner similar to previous work [22]. Data extracted included patient demographics, height, weight, American Society for Anesthesiologists Physical Status (ASA-PS) classification, inpatient status, smoking status, numerous comorbidities, operative time, whether a concurrent procedure was performed, and various postoperative complications.

Body mass index (BMI) was calculated for all patients using height and weight data. Patients missing height or weight data were excluded. Patients were assigned into groups based on calculated BMI (non-overweight $<25$, overweight 25 to $<30$, class 1 obesity 30 to $<35$, class 2 obesity 35 to $<40$, and class 3 obesity $\geq 40$ ) as categorized by the World Health Organization [23]. Complications were assigned as surgical, wound, or medical. Surgical complications included an unplanned return to the operating room and unplanned related readmission within 30 days. Wound complications included varying degrees of surgical site infection and wound dehiscence.

\section{Statistical Analysis}

Rates of complications were compared across BMI groups using chi-square and linear regression analyses. Patient characteristics and perioperative variables were compared between patients with and without a postoperative complication using chi-square or Fischer's exact test, where appropriate. Univariate and multivariable logistic regressions were used to calculate the odds of a surgical, wound, or medical complication across BMI groups. Multivariable regressions were adjusted for sex, age, race, ASA-PS classification, inpatient status, smoking status, comorbidities, and perioperative variables with a significant difference in univariate analysis. Statistical significance was assigned a $p$-value threshold of 0.05. Analyses were completed using SPSS V24 (IBM Armonk, NY).

\section{Results}

\section{Patient Sample and Complications}

A total of 12,803 patients undergoing panniculectomy were identified in the 2012-2018 NSQIP database. Seventy-one patients were excluded due to missing height and/or weight data, leaving 12,732 patients in the final sample. Of these patients, 1759 (13.8\%) experienced at least one postoperative complication. Included in these, $882(6.9 \%)$ had one or more surgical complications, $853(6.7 \%)$ had one or more wound complications, and $735(5.8 \%)$ had one or more medical complications (Table 1). When compared across BMI groups, patients in higher groups were more likely to experience at least one medical, wound, or surgical complication in a stepwise fashion $(p<0.001)$ (Fig. 1). On linear regression, BMI category was highly correlated with the rate of at least one postoperative complication $\left(R^{2}=0.91\right.$, $p=0.012)$ as well as the rate of specifically surgical $\left(R^{2}=0.85, p=0.027\right)$, wound $\left(R^{2}=0.92, p=0.009\right)$, and medical complications $\left(R^{2}=0.84, p=0.028\right)$. 
Table 1 Rates of complications following panniculectomy by body mass index range

\begin{tabular}{|c|c|c|c|c|c|c|c|c|c|c|c|c|c|}
\hline & \multicolumn{2}{|c|}{$\begin{array}{l}\text { Total cohort } \\
(n=12,732)\end{array}$} & \multicolumn{2}{|c|}{$\begin{array}{l}\text { Non-overweight } \\
(n=2196,17.2 \%)\end{array}$} & \multicolumn{2}{|c|}{$\begin{array}{l}\text { Overweight } \\
(n=4128,32.4 \%)\end{array}$} & \multicolumn{2}{|c|}{$\begin{array}{l}\text { Class 1 } \\
(n=3288, \\
25.8 \%)\end{array}$} & \multicolumn{2}{|c|}{$\begin{array}{l}\text { Class } 2 \\
(n=1592, \\
12.5 \%)\end{array}$} & \multicolumn{2}{|c|}{$\begin{array}{l}\text { Class } 3 \\
(n=1528, \\
12.0 \%)\end{array}$} & \multirow[t]{2}{*}{$p$-value } \\
\hline & $N$ & $\%$ & $N$ & $\%$ & $N$ & $\%$ & $N$ & $\%$ & $N$ & $\%$ & $N$ & $\%$ & \\
\hline Any complication & 1759 & $13.8 \%$ & 144 & $6.6 \%$ & 384 & $9.3 \%$ & 459 & $14.0 \%$ & 295 & $18.5 \%$ & 477 & $31.2 \%$ & $<0.001$ \\
\hline Surgical complication & 882 & $6.9 \%$ & 74 & $3.4 \%$ & 191 & $4.6 \%$ & 231 & $7.0 \%$ & 133 & $8.4 \%$ & 253 & $16.6 \%$ & $<0.001$ \\
\hline Unplanned return to OR & 484 & $3.8 \%$ & 47 & $2.1 \%$ & 114 & $2.8 \%$ & 113 & $3.4 \%$ & 61 & $3.8 \%$ & 131 & $8.6 \%$ & $<0.001$ \\
\hline Unplanned readmission & 660 & $5.2 \%$ & 49 & $2.2 \%$ & 132 & $3.2 \%$ & 166 & $5.0 \%$ & 111 & $7.0 \%$ & 202 & $13.2 \%$ & $<0.001$ \\
\hline Wound complication & 853 & $6.7 \%$ & 46 & $2.1 \%$ & 167 & $4.0 \%$ & 208 & $6.3 \%$ & 165 & $10.4 \%$ & 267 & $17.5 \%$ & $<0.001$ \\
\hline Superficial SSI & 506 & $4.0 \%$ & 26 & $1.2 \%$ & 102 & $2.5 \%$ & 135 & $4.1 \%$ & 93 & $5.8 \%$ & 150 & $9.8 \%$ & $<0.001$ \\
\hline Deep SSI & 185 & $1.5 \%$ & 11 & $0.5 \%$ & 34 & $0.8 \%$ & 44 & $1.3 \%$ & 36 & $2.3 \%$ & 60 & $3.9 \%$ & $<0.001$ \\
\hline Organ/space SSI & 48 & $0.4 \%$ & 1 & $0.0 \%$ & 9 & $0.2 \%$ & 11 & $0.3 \%$ & 11 & $0.7 \%$ & 16 & $1.0 \%$ & $<0.001$ \\
\hline Wound disruption & 162 & $1.3 \%$ & 8 & $0.4 \%$ & 34 & $0.8 \%$ & 29 & $0.9 \%$ & 34 & $2.1 \%$ & 57 & $3.7 \%$ & $<0.001$ \\
\hline Medical complication & 735 & $5.8 \%$ & 61 & $2.8 \%$ & 169 & $4.1 \%$ & 189 & $5.7 \%$ & 109 & $6.8 \%$ & 207 & $13.5 \%$ & $<0.001$ \\
\hline Pneumonia & 33 & $0.3 \%$ & 1 & $0.0 \%$ & 4 & $0.1 \%$ & 4 & $0.1 \%$ & 5 & $0.3 \%$ & 19 & $1.2 \%$ & $<0.001$ \\
\hline Pulmonary embolism & 51 & $0.4 \%$ & 7 & $0.3 \%$ & 10 & $0.2 \%$ & 16 & $0.5 \%$ & 8 & $0.5 \%$ & 10 & $0.7 \%$ & 0.168 \\
\hline Reintubate & 16 & $0.1 \%$ & 2 & $0.1 \%$ & 1 & $0.0 \%$ & 0 & $0.0 \%$ & 4 & $0.3 \%$ & 9 & $0.6 \%$ & $<0.001$ \\
\hline Ventilate at 48 hours & 25 & $0.2 \%$ & 1 & $0.0 \%$ & 1 & $0.0 \%$ & 1 & $0.0 \%$ & 5 & $0.3 \%$ & 17 & $1.1 \%$ & $<0.001$ \\
\hline Deep vein thrombosis & 59 & $0.5 \%$ & 5 & $0.2 \%$ & 14 & $0.3 \%$ & 14 & $0.4 \%$ & 11 & $0.7 \%$ & 15 & $1.0 \%$ & 0.005 \\
\hline Acute renal failure & 10 & $0.1 \%$ & 0 & $0.0 \%$ & 0 & $0.0 \%$ & 0 & $0.0 \%$ & 2 & $0.1 \%$ & 8 & $0.5 \%$ & $<0.001$ \\
\hline Urinary tract infection & 78 & $0.6 \%$ & 7 & $0.3 \%$ & 24 & $0.6 \%$ & 22 & $0.7 \%$ & 7 & $0.4 \%$ & 18 & $1.2 \%$ & 0.016 \\
\hline Stroke & 4 & $0.0 \%$ & 0 & $0.0 \%$ & 0 & $0.0 \%$ & 2 & $0.1 \%$ & 1 & $0.1 \%$ & 1 & $0.1 \%$ & 0.412 \\
\hline Cardiac arrest & 7 & $0.1 \%$ & 0 & $0.0 \%$ & 2 & $0.0 \%$ & 2 & $0.1 \%$ & 0 & $0.0 \%$ & 3 & $0.2 \%$ & 0.104 \\
\hline Myocardial infarction & 8 & $0.1 \%$ & 0 & $0.0 \%$ & 1 & $0.0 \%$ & 3 & $0.1 \%$ & 0 & $0.0 \%$ & 4 & $0.3 \%$ & 0.009 \\
\hline Other bleed & 475 & $3.7 \%$ & 39 & $1.8 \%$ & 108 & $2.6 \%$ & 131 & $4.0 \%$ & 69 & $4.3 \%$ & 128 & $8.4 \%$ & $<0.001$ \\
\hline Sepsis & 87 & $0.7 \%$ & 4 & $0.2 \%$ & 15 & $0.4 \%$ & 10 & $0.3 \%$ & 17 & $1.1 \%$ & 41 & $2.7 \%$ & $<0.001$ \\
\hline
\end{tabular}

Bold $p$-values significant at threshold of 0.05

$O R$ operating room, SSI surgical site infection

Fig. 1 Prevalence of complications following panniculectomy by body mass index range. All trends $p<0.001$

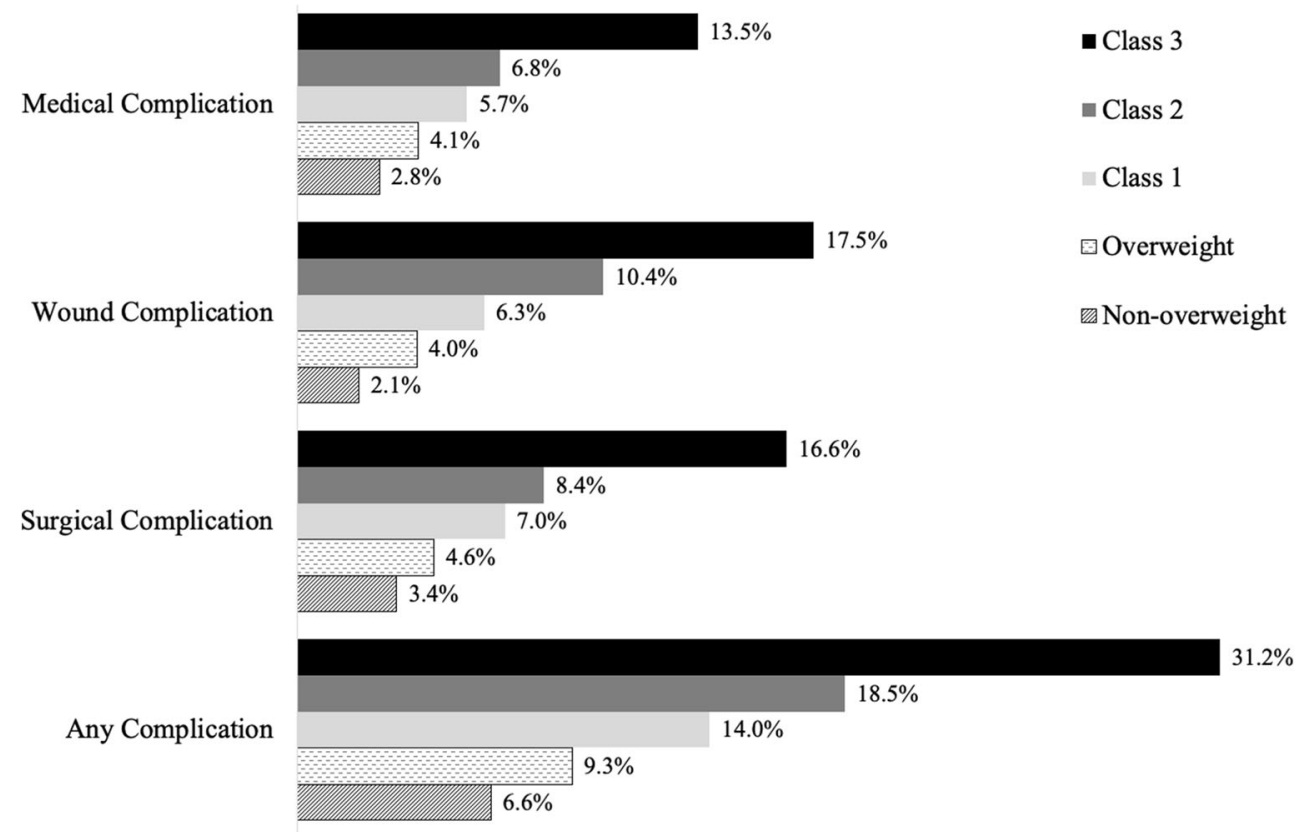




\section{Characteristics of Patients with Complications}

Patients experiencing at least one postoperative complication were more likely to be male $(16.9 \%$ vs. $10.1 \%, p<0.001)$, older $(p<0.001)$, in a higher BMI group $(p<0.001)$, of a higher ASA-PS classification $(p<0.001)$, inpatient $(60.8 \%$ vs. $33.5 \%$, $p<0.001)$, or a smoker (12.4\% vs. $8.9 \%, p<0.001)$. Additionally, patients with comorbidities were more likely to have numerous complications including diabetes mellitus ( $19.2 \%$ vs. $9.6 \%, p<0.001)$, hypertension (39.2\% vs. $24.5 \%$, $p<0.001)$, congestive heart failure $(0.8 \%$ vs. $0.2 \%, p<0.001)$, chronic obstructive pulmonary disease $(3.9 \%$ vs. $1.1 \%$, $p<0.001)$, a bleeding disorder $(2.0 \%$ vs. $1.0 \%, p<0.001)$, or be taking steroids chronically $(3.0 \%$ vs. $1.6 \%, p<0.001)$. Patients with a complication were less likely to be undergoing a concurrent procedure in the operating room (55.8\% vs. $60.6 \%, p<0.001$ ) (Table 2). Similar differences were seen between patients with and without specifically surgical (Table S1), wound (Table S2), or medical complications (Table S3).

\section{Predicting the Odds of Complications Following Panniculectomy}

Following adjustment for demographics, comorbidities, and perioperative factors significant on univariate analysis, patients who were overweight $(\mathrm{OR}=1.24, p=0.039)$ or had class $1(\mathrm{OR}=1.72, p<0.001)$, class $2(\mathrm{OR}=2.10, p<0.001)$, or class 3 $(\mathrm{OR}=3.01, p<0.001)$ obesity were more likely to experience at least one postoperative complication (Table 3$)$. More specifically, patients with class $1(\mathrm{OR}=1.58, p=0.001)$, class 2 $(\mathrm{OR}=1.58, p=0.004)$, or class $3(\mathrm{OR}=2.39, p<0.001)$ obesity were more likely to experience a surgical complication. Additionally, overweight patients $(\mathrm{OR}=1.77, p=0.001)$ or patients with class $1(\mathrm{OR}=2.59, p<0.001)$, class $2(\mathrm{OR}=4.05$, $p<0.001)$, or class $3(\mathrm{OR}=5.84, p<0.001)$ obesity were more likely to have a wound complication. Lastly, patients with class $1(\mathrm{OR}=1.45, p=0.017)$, class $2(\mathrm{OR}=1.48, p=0.025)$, or class $3(\mathrm{OR}=2.11, p<0.001)$ were more likely to have a postoperative medical complication.

\section{Discussion}

Body contouring procedures, including abdominoplasties and panniculectomies, are frequent adjuncts to bariatric surgery, often performed not only for cosmetic indications but also for functional reasons [24, 25]. Receiving such procedures after gastric bypass surgery has been demonstrated to improve long-term quality of life, positively affecting patients' selfesteem and improving their social lives, work-ability, sexual activity, and physical activity [26]. This desire to pursue body contouring surgeries post-bariatric surgery was demonstrated by Kitzinger et al., who, based on survey data, showed that $74 \%$ of all patients who received bariatric surgery also desired a body contouring procedure [25].

As such, patients undergoing body contouring surgeries are often obese with multiple comorbidities that may be related to their underlying obesity $[27,28]$. Among the comorbidities most frequently attributed to obesity are type 2 diabetes mellitus, gallbladder disease, osteoarthritis, hypertension, coronary artery disease, breast cancer, and colon cancer [27]. Thus, among our cohort of patients receiving panniculectomies, the prevalence of hypertension $(26.5 \%)$, diabetes mellitus $(10.9 \%)$, chronic obstructive pulmonary disease $(1.5 \%)$, and congestive heart failure $(0.3 \%)$ is unsurprising (Table 2). Current smoking status $(9.3 \%)$ and chronic steroid use $(1.8 \%)$ were also seen in several members of our study group, highlighting the complex interplay between contributing factors for obesity. While the association between smoking and obesity is multifaceted, with studies demonstrating both protective and contributing relationships towards obesity, chronic steroid use has been well-known to have an influential role in the development of obesity [29, 30]. It is also unsurprising to see that patients who experience complications following panniculectomy are more likely to have the aforementioned comorbidities (Table 2). This makes particular sense for patients with diabetes, which, like smoking, is known to impact wound healing and thus predispose to wound complications [31-35]. Indeed, diabetes mellitus has previously been demonstrated to be an independent risk factor for post-panniculectomy wound dehiscence. In this same study, smoking status increased the odds of superficial and deep surgical site infections, similar to our findings [20]. These findings highlight the need for preoperative evaluation of all patients receiving panniculectomies to determine the risk factors that predispose them to complications.

Patients undergoing panniculectomy were most frequently middle-aged white women, while those most likely to experience complications following panniculectomy were most frequently older white men (Table 2). This relationship between advanced age and post-panniculectomy complications was illustrated by an earlier analysis of the NSQIP database by Cammarata et al. [22] Their analysis of 7030 patients receiving panniculectomies demonstrated an odds ratio of 1.46 for developing complications in patients aged greater than 65 compared to their younger counterparts. Cammarata et al. speculated that possible causes for this association include the overall decreased energy reserve in this population and the known effects of aging on wound healing. Similarly, male sex and older age were demonstrated to be significant predictors of postoperative complications by Gmur et al. in their retrospective analysis of 73 patients undergoing abdominoplasty with or without dermolipectomy [36].

Complications following panniculectomy are not uncommon, seen in $13.8 \%$ of the cases included for analysis. Of 
Table 2 Characteristics of patients and procedures with and without a complication following panniculectomy

Total cohort $(n=12,732) \quad$ No complication $(n=10,973,86.2 \%)$ Any complication $(n=1759,13.8 \%) \quad$ P-value

N $\%$

N $\%$

$\%$

\begin{tabular}{|c|c|c|c|c|c|c|c|}
\hline \multicolumn{7}{|l|}{ Sex } & \multirow[t]{3}{*}{$<0.001$} \\
\hline Female & 11,326 & $89.0 \%$ & 9865 & $89.9 \%$ & 1461 & $83.1 \%$ & \\
\hline Male & 1406 & $11.0 \%$ & 1108 & $10.1 \%$ & 298 & $16.9 \%$ & \\
\hline Age & & & & & & & $<0.001$ \\
\hline $18-40$ & 4438 & $34.9 \%$ & 3962 & $36.1 \%$ & 476 & $27.1 \%$ & \\
\hline $41-65$ & 7388 & $58.0 \%$ & 6278 & $57.2 \%$ & 1110 & $63.1 \%$ & \\
\hline$>65$ & 906 & $7.1 \%$ & 733 & $6.7 \%$ & 173 & $9.8 \%$ & \\
\hline Race & & & & & & & 0.028 \\
\hline White & 8554 & $67.2 \%$ & 7319 & $66.7 \%$ & 1235 & $70.2 \%$ & \\
\hline Black & 1705 & $13.4 \%$ & 1483 & $13.5 \%$ & 222 & $12.6 \%$ & \\
\hline Other & 226 & $1.8 \%$ & 197 & $1.8 \%$ & 29 & $1.6 \%$ & \\
\hline Unknown & 2247 & $17.6 \%$ & 1974 & $18.0 \%$ & 273 & $15.5 \%$ & \\
\hline BMI category & & & & & & & $<0.001$ \\
\hline Non-overweight & 2196 & $17.2 \%$ & 2052 & $18.7 \%$ & 144 & $8.2 \%$ & \\
\hline Overweight & 4128 & $32.4 \%$ & 3744 & $34.1 \%$ & 384 & $21.8 \%$ & \\
\hline Class 1 & 3288 & $25.8 \%$ & 2829 & $25.8 \%$ & 459 & $26.1 \%$ & \\
\hline Class 2 & 1592 & $12.5 \%$ & 1297 & $11.8 \%$ & 295 & $16.8 \%$ & \\
\hline Class 3 & 1528 & $12.0 \%$ & 1051 & $9.6 \%$ & 477 & $27.1 \%$ & \\
\hline ASA & & & & & & & $<0.001$ \\
\hline PS1 & 2082 & $16.4 \%$ & 1959 & $17.9 \%$ & 123 & $7.0 \%$ & \\
\hline PS2 & 7459 & $58.6 \%$ & 6597 & $60.1 \%$ & 862 & $49.0 \%$ & \\
\hline PS3 or greater & 3176 & $24.9 \%$ & 2404 & $21.9 \%$ & 772 & $43.9 \%$ & \\
\hline Inpatient & 4750 & $37.3 \%$ & 3681 & $33.5 \%$ & 1069 & $60.8 \%$ & $<0.001$ \\
\hline Current smoker & 1190 & $9.3 \%$ & 972 & $8.9 \%$ & 218 & $12.4 \%$ & $<0.001$ \\
\hline Diabetes & 1392 & $10.9 \%$ & 1055 & $9.6 \%$ & 337 & $19.2 \%$ & $<0.001$ \\
\hline Hypertension & 3377 & $26.5 \%$ & 2687 & $24.5 \%$ & 690 & $39.2 \%$ & $<0.001$ \\
\hline Congestive heart failure & 36 & $0.3 \%$ & 22 & $0.2 \%$ & 14 & $0.8 \%$ & $<0.001$ \\
\hline Chronic obstructive pulmonary disease & 185 & $1.5 \%$ & 116 & $1.1 \%$ & 69 & $3.9 \%$ & $<0.001$ \\
\hline Bleeding disorder & 146 & $1.1 \%$ & 110 & $1.0 \%$ & 36 & $2.0 \%$ & $<0.001$ \\
\hline Disseminated cancer & 7 & $0.1 \%$ & 5 & $0.0 \%$ & 2 & $0.1 \%$ & 0.250 \\
\hline Recent weight loss & 33 & $0.3 \%$ & 25 & $0.2 \%$ & 8 & $0.5 \%$ & 0.122 \\
\hline Chronic steroid use & 229 & $1.8 \%$ & 177 & $1.6 \%$ & 52 & $3.0 \%$ & $<0.001$ \\
\hline Concurrent procedure & 7631 & $59.9 \%$ & 6649 & $60.6 \%$ & 982 & $55.8 \%$ & $<0.001$ \\
\hline Longer operative time ( $\geq 215$ minutes) & 3190 & $25.1 \%$ & 2727 & $24.9 \%$ & 463 & $26.3 \%$ & 0.187 \\
\hline
\end{tabular}

Bold $p$-values significant at threshold of 0.05

$B M I$ body mass index, ASA-PS American Society for Anesthesiologists Physical Status

these, surgical complications were most common, seen in $6.9 \%$ of the cases, followed by wound complications, seen in $6.7 \%$ of cases, and medical complications, seen in $5.8 \%$ of cases (Table 1). Similar to complications reported by Cooper et al., Manahan et al., and Acarturk et al., the most common complications include unplanned readmissions within 30 days of discharge (5.2\%), unplanned return to the operating room (3.8\%), superficial surgical site infections (4.0\%), deep surgical site infections (1.5\%), wound disruptions
(1.3\%), and bleeding $(3.7 \%)$ (Table 1) [11, 17, 19]. The relatively high prevalence of these complications may be influenced by the increased disease burden in the patient population receiving these surgeries. Panniculectomies often involve removing a large amount of skin and fat in patients who already have severe underlying abdominal deformities [37]. Thus, the combination of a highly involved surgery with numerous preoperative comorbidities results in an expansive complication profile. 
Table 3 Body mass index category and odds for postoperative complications following panniculectomy

\begin{tabular}{|c|c|c|c|c|c|c|c|c|c|c|c|c|c|c|c|c|}
\hline & \multicolumn{4}{|c|}{ Any complication } & \multicolumn{4}{|c|}{ Surgical complication } & \multicolumn{4}{|c|}{ Wound complication } & \multicolumn{4}{|c|}{ Medical complication } \\
\hline & OR & $\begin{array}{l}p- \\
\text { value }\end{array}$ & $\mathrm{aOR}$ & $\begin{array}{l}p- \\
\text { value }\end{array}$ & OR & $\begin{array}{l}p- \\
\text { value }\end{array}$ & $\mathrm{aOR}$ & $\begin{array}{l}p- \\
\text { value }\end{array}$ & OR & $\begin{array}{l}p- \\
\text { value }\end{array}$ & $\mathrm{aOR}$ & $\begin{array}{l}p- \\
\text { value }\end{array}$ & OR & $\begin{array}{l}p- \\
\text { value }\end{array}$ & $\mathrm{aOR}$ & $\begin{array}{l}p- \\
\text { value }\end{array}$ \\
\hline Non-overweight & \multicolumn{2}{|c|}{ Reference } & \multicolumn{2}{|c|}{ Reference } & \multicolumn{2}{|c|}{ Reference } & \multicolumn{2}{|c|}{ Reference } & \multicolumn{2}{|c|}{ Reference } & \multicolumn{2}{|c|}{ Reference } & \multicolumn{2}{|c|}{ Reference } & \multicolumn{2}{|c|}{ Reference } \\
\hline Overweight & 1.46 & $<0.001$ & 1.24 & 0.039 & 1.39 & 0.018 & 1.18 & 0.250 & 1.97 & $<0.001$ & 1.77 & 0.001 & 1.49 & 0.008 & 1.21 & 0.226 \\
\hline Class 1 & 2.31 & $<0.001$ & 1.72 & $<0.001$ & 2.17 & $<0.001$ & 1.58 & 0.001 & 3.16 & $<0.001$ & 2.59 & $<0.001$ & 2.14 & $<0.001$ & 1.45 & 0.017 \\
\hline Class 2 & 3.24 & $<0.001$ & 2.10 & $<0.001$ & 2.61 & $<0.001$ & 1.58 & 0.004 & 5.40 & $<0.001$ & 4.05 & $<0.001$ & 2.57 & $<0.001$ & 1.48 & 0.025 \\
\hline Class 3 & 6.47 & $<0.001$ & 3.01 & $<0.001$ & 5.69 & $<0.001$ & 2.39 & $<0.001$ & 9.90 & $<0.001$ & 5.84 & $<0.001$ & 5.48 & $<0.001$ & 2.11 & $<0.001$ \\
\hline
\end{tabular}

Odds ratios (OR) reflect named body mass index category relative to non-overweight patients. Adjusted odds ratios (aOR) controlled for sex, age, race, ASA-PS classification, inpatient status, smoking status, comorbidities, and perioperative variables differing significantly on univariate analysis. Bold $p$ values significant at threshold of 0.05

Based on our study, the rates of surgical, medical, and wound complications all increased with increasing BMI category such that class 3 obesity was associated with the highest rates of all three categories of complications. Even after adjusting for various pre- and perioperative variables, increasing BMI class conferred an increased odds of developing any postoperative complication (Table 3 ). This finding is supported by Arthurs et al., who similarly demonstrated that prepanniculectomy BMI was an independent predictor for developing postoperative complications including seroma, hematoma, surgical site infections, skin breakdown/necrosis, and reexploration, with BMIs greater than 25 resulting in nearly three times the risk of wound complications [18]. In assessing the complication rates associated with class 3 obesity patients following panniculectomy, Al Qattan et al. similarly demonstrated that patients in this highest BMI category had significantly higher rates of wound and medical complications, a finding also echoed by Zannis et al. in their retrospective review of 563 patients following panniculectomy [38, 39]. Al Qattan et al. explain that a possible mechanism for this increased rate of complications in higher BMI categories includes the chronic inflammatory state conferred by obesity, resulting in increased levels of pro-inflammatory cytokines such as tumor necrosis factor-alpha, interleukin-6, and interleukin- $1 \mathrm{~b}$, all of which are produced in higher levels in obese patients, which in turn result in poor wound healing and possible complications $[38,40,41]$. Arthurs et al. further add that it may be valuable to include BMI in preoperative assessments of patients to determine which patients would be the best candidates for panniculectomy and derive the greatest benefit with the least risk of harm [18]. Another important consideration that Rawlins adds is that the complication profile experienced by patients may be influenced by not only the procedure itself but also by the method of weight loss procedure they undergo [18]. For example, the clinical impact of a midline incision as opposed to laparoscopic port incisions may predispose to varying forms of complications that our study does not directly address [18].
This study provides much-needed insight into a vulnerable surgical population, potentially helping to guide perioperative management and highlighting the need for comprehensive preoperative risk factor assessments for these patients. Despite this, there are several limitations to the study. First, NSQIP only collects data for complications occurring up to 30 days following surgery. This may lead to underreporting of complications and limits the type and range of complications that can be analyzed following surgery. Second, the database does not include all pertinent variables, such as antibiotic use in the operating room or panniculus size, limiting the factors that may be accounted for. Third, previous surgeries are not coded in NSQIP, which prevents researchers from knowing the direct cause of the panniculus [22]. Last, the retrospective design of this study does not allow for statements of causality. That being said, this study also has numerous strengths. This is one of the first studies to thoroughly study the complications following panniculectomy as it relates to preoperative BMI. Our large national multi-institutional sample allows us to study clinically pertinent associations more definitively than numerous previous studies.

\section{Conclusion}

Complications commonly occur following panniculectomy. As BMI increases, patients are more likely to experience all types of complications in a dose-dependent manner. This finding is particularly strong for wound healing complications, including postoperative infection and dehiscence.

Supplementary Information The online version contains supplementary material available at https://doi.org/10.1007/s11695-021-05468-w.

\section{Declarations}

Ethics Approval The Institutional Review Board of Rutgers New Jersey Medical School does not consider work done with publicly available de- 
identified databases to be human subject research; therefore, approval for this study was not required.

Informed Consent Informed consent does not apply.

Conflict of Interest The authors declare no competing interest.

\section{References}

1. Swinburn BA, Sacks G, Hall KD, et al. The global obesity pandemic: shaped by global drivers and local environments. Lancet. 2011;378(9793):804-14.

2. Chriqui JF. Obesity prevention policies in U.S. states and localities: lessons from the field. Curr Obes Rep. 2013;2(3):200-10.

3. Wang Y, Beydoun MA, Min J, et al. Has the prevalence of overweight, obesity and central obesity levelled off in the United States? Trends, patterns, disparities, and future projections for the obesity epidemic. Int J Epidemiol. 2020;49:810-23.

4. Hales CM, Carroll MD, Fryar CD, Ogden CL. Prevalence of obesity and severe obesity among adults: United States, 2017-2018. NCHS Data Brief. 2020;(360):1-8.

5. Clemmensen C, Petersen MB, Sørensen TI. Will the COVID-19 pandemic worsen the obesity epidemic? Nat Rev Endocrinol. 2020;16(9):469-70.

6. Finkelstein EA, Khavjou OA, Thompson H, et al. Obesity and severe obesity forecasts through 2030. Am J Prev Med. 2012;42(6):563-70.

7. English WJ, DeMaria EJ, Brethauer SA, et al. American Society for Metabolic and Bariatric Surgery estimation of metabolic and bariatric procedures performed in the United States in 2016. Surg Obes Relat Dis. 2018;14(3):259-63.

8. Borud LJ, Warren AG. Body contouring in the postbariatric surgery patient. J Am Coll Surg. 2006;203(1):82-93.

9. Petty P, Manson PN, Black R, et al. Panniculus morbidus. Ann Plast Surg. 1992;28(5):442-52.

10. Hopkins MP, Shriner AM, Parker MG, et al. Panniculectomy at the time of gynecologic surgery in morbidly obese patients. Am J Obstet Gynecol. 2000;182(6):1502-5.

11. Acarturk TO, Wachtman G, Heil B, et al. Panniculectomy as an adjuvant to bariatric surgery. Ann Plast Surg. 2004;53(4):360-6.

12. Zemlyak AY, Colavita PD, El Djouzi S, et al. Comparative study of wound complications: isolated panniculectomy versus panniculectomy combined with ventral hernia repair. J Surg Res. 2012;177(2):387-91.

13. Mioton LM, Buck DW, Gart MS, et al. A multivariate regression analysis of panniculectomy outcomes: does plastic surgery training matter? Plast Reconstr Surg. 2013;131(4):604e-12e.

14. Pratt JH, Irons GB. Panniculectomy and abdominoplasty. Am J Obstet Gynecol. 1978;132(2):165-8.

15. Lesko RP, Cheah MA, Sarmiento S, et al. Postoperative complications of panniculectomy and abdominoplasty: a retrospective review. Ann Plast Surg. 2020;85(3):285-9.

16. Derickson M, Phillips C, Barron M, et al. Panniculectomy after bariatric surgical weight loss: analysis of complications and modifiable risk factors. Am J Surg. 2018;215(5):887-90.

17. Cooper JM, Paige KT, Beshlian KM, et al. Abdominal panniculectomies: high patient satisfaction despite significant complication rates. Ann Plast Surg. 2008;61(2):188-96.

18. Arthurs ZM, Cuadrado D, Sohn V, et al. Post-bariatric panniculectomy: pre-panniculectomy body mass index impacts the complication profile. Am J Surg. 2007;193(5):567-70.
19. Manahan MA, Shermak MA. Massive panniculectomy after massive weight loss. Plast Reconstr Surg. 2006;117(7):2191-7.

20. Kantar RS, Rifkin WJ, Wilson SC, et al. Abdominal panniculectomy: determining the impact of diabetes on complications and risk factors for adverse events. Plast Reconstr Surg. 2018;142(4):462e-71e.

21. Khuri SF. The NSQIP: a new frontier in surgery. Surgery. 2005;138(5):837-43.

22. Cammarata MJ, Kantar RS, Rifkin WJ, et al. Advanced age is a risk factor for complications following abdominal panniculectomy. Obes Surg. 2019;29(2):426-33.

23. Organization WH. Obesity: preventing and managing the global epidemic. Report of a WHO consultation. World Health Organ Tech Rep Ser. 2000;894:ixii, 1-253.

24. Mitchell JE, Crosby RD, Ertelt TW, et al. The desire for body contouring surgery after bariatric surgery. Obes Surg. 2008;18(10):1308-12.

25. Kitzinger HB, Abayev S, Pittermann A, et al. The prevalence of body contouring surgery after gastric bypass surgery. Obes Surg. 2012;22(1):8-12.

26. Modarressi A, Balague N, Huber O, et al. Plastic surgery after gastric bypass improves long-term quality of life. Obes Surg. 2013;23(1):24-30.

27. Aronne LJ. Classification of obesity and assessment of obesityrelated health risks. Obes Res. 2002;10(S12):105S-15S.

28. Schelbert KB. Comorbidities of obesity. Prim Care. 2009;36(2): 271-85.

29. Dare S, Mackay DF, Pell JP. Relationship between smoking and obesity: a cross-sectional study of 499,504 middle-aged adults in the UK general population. PLoS One. 2015;10(4):e0123579.

30. Dallman MF, Pecoraro NC, La Fleur SE, et al. Glucocorticoids, chronic stress, and obesity. Prog Brain Res. 2006;153:75-105.

31. Okonkwo UA, DiPietro LA. Diabetes and wound angiogenesis. Int J Mol Sci. 2017;18(7):1419.

32. Greenhalgh DG. Wound healing and diabetes mellitus. Clin Plast Surg. 2003;30(1):37-45.

33. Christman AL, Selvin E, Margolis DJ, et al. Hemoglobin A1c predicts healing rate in diabetic wounds. J Investig Dermatol. 2011;131(10):2121-7.

34. Jensen JA, Goodson WH, Hopf HW, et al. Cigarette smoking decreases tissue oxygen. Arch Surg. 1991;126(9):1131-4.

35. Kean J. The effects of smoking on the wound healing process. J Wound Care. 2010;19(1):5-8.

36. Gmür RU, Banic A, Erni D. Is it safe to combine abdominoplasty with other dermolipectomy procedures to correct skin excess after weight loss? Ann Plast Surg. 2003;51(4):353-7.

37. Gusenoff JA. Abdomen: panniculectomy and abdominoplasty. In: Managing body contouring challenges and complications. 1st Edition, Springer International Publishing; 2019. p. 17-43.

38. AlQattan HT, Mundra LS, Rubio GA, et al. Abdominal contouring outcomes in class III obesity: analysis of the ACS-NSQIP database. Aesthet Plast Surg. 2018;42(1):13-20.

39. Zannis J, Wood BC, Griffin LP, et al. Outcome study of the surgical management of panniculitis. Ann Plast Surg. 2012;68(2):194-7.

40. Bell TM, Bayt DR, Siedlecki CB, et al. Infectious complications in obese patients after trauma. J Surg Res. 2016;204(2):393-7.

41. Green WD, Beck MA. Obesity altered T cell metabolism and the response to infection. Curr Opin Immunol. 2017;46:1-7.

Publisher's Note Springer Nature remains neutral with regard to jurisdictional claims in published maps and institutional affiliations. 